\title{
O Processo Avaliativo do ROODA: uma proposta interdisciplinar *
}

Prof $^{a}$. Dra . Patricia Alejandra Behar - pbehar@terra.com.br

M.Sc. Sílvia Meirelles Leite - silviameirelles@gmail.com

Sandra Bordini Mazzocato - sandrabordini@gmail.com

Lúcia Barros de Souza - daurealu@yahoo.com.br

Luciano Goularte Siqueira - lgoularte@gmail.com

Núcleo de Tecnologias Digitais Aplicadas à Educação (NUTED)

Universidade Federal do Rio Grande do Sul (UFRGS)

Resumo: Este artigo trata do processo avaliativo realizado com o ROODA (Rede cOOperativa De Aprendizagem), um Ambiente Virtual de Aprendizagem (AVA) disponível via Web, que tem como objetivo dar suporte à educação presencial e à distância. O ROODA foi desenvolvido pelo NUTED/UFRGS e integra o projeto de Educação à Distância desta universidade. A institucionalização deste ambiente envolveu a sua adequação às necessidades da UFRGS, sendo este um dos principais norteadores na avaliação. Também se destaca o caráter interdisciplinar deste processo avaliativo, tendo em vista as especificidades das áreas do conhecimento envolvidas no seu desenvolvimento. A partir disto, apresentam-se os quatro princípios avaliativos que subsidiaram o aperfeiçoamento deste AVA, os procedimentos utilizados para a coleta de dados e as principais reformulações feitas no ROODA.

Palavras-chave: ambiente virtual de aprendizagem, avaliação, institucionalização, interdisciplinaridade.

Abstract: This article discusses the processes evaluation performed with the ROODA (Cooperative Learning Network), a Virtual Learning Environment (AVA) available in the web, that supports long distance as well as presencial education. The ROODA it was development for NUTED/UFRGS and integrates Distant Teaching Project of this university. For the Institutionalization of this environment it was necessary to adapt it to the UFRGS's needs. Its interdisciplinary proposal of this processes evaluation stand out, looking at the specificity of the knowledge areas enveloped in it's development. As from this are present the four evaluation principles that subsidize the perfection of this $A V A$, the proceeding utilized to the data collection and the principal reformulations makes in ROODA.

Keywords: learning virtual environment, evaluation, institutionalization, interdisciplinarity.

\section{The processes evaluation of the ROODA: a interdisciplinary proposal}

\section{Introdução}

$\mathrm{O}$ artigo discute o processo avaliativo de Ambientes Virtuais de Aprendizagem (AVA) ${ }^{\mathrm{i}}$ a partir de uma perspectiva interdisciplinar e interacionista, a fim de analisar a performance técnica e as demandas dos usuários. Para isso, apresenta a avaliação realizada com o ROODA (Rede cOOperativa De Aprendizagem), um AVA que integra o projeto de Educação a Distância da Universidade Federal do Rio Grande do Sul (UFRGS).

\footnotetext{
* Esta pesquisa conta com o apoio financeiro do Conselho Nacional de Desenvolvimento Científico e Tecnológico (CNPq) e da Secretaria de Educação à Distância da Universidade Federal do Rio Grande do Sul (SEAD/UFRGS). V. $4 \mathrm{~N}^{\circ}$ 1, Julho, 2006
} 
O ROODA começou a ser desenvolvido em 2000 pelo Núcleo de Tecnologias Digitais aplicadas à Educação (NUTED) da UFRGS. Em 2003, tornou-se uma das plataformas de aprendizagem oficiais da instituição. Logo, iniciou-se a construção de uma nova versão, envolvendo: pesquisa sobre as demandas docentes e discentes; reprogramação de todo o sistema, reconstrução da interface gráfica; planejamento de novas funcionalidades e elaboração de uma documentação para o usuário.

A nova versão do ROODA, que está disponível em http://www.ead.ufrgs.br/rooda, caracteriza-se por ser centrada no usuário e oferecer funcionalidades que possibilitam: compartilhamento de produções; interação síncrona e assíncrona; registros pessoais; gerenciamento de disciplinas/cursos; configuração do sistema e personalização a interface gráfica. É um software livre feito com linguagem PHP e banco de dados MySQL e tem licença GPL. Para acessar o ROODA, usa-se o mesmo login e senha do portal de servidor/aluno da UFRGS (Behar, Primo, Leite, 2005).

Destaca-se a importância do processo de institucionalização do ROODA para a sua avaliação, pois os critérios usados foram elaborados dentro deste contexto, bem como a coleta de dados e a definição das prioridades. De acordo com Leite (2005) as avaliações são organizadores qualificados e de caráter pedagógico, que dão subsídios para a aprendizagem organizacional. Assim, construiu-se uma metodologia avaliativa baseada na institucionalização do ambiente, no processo de integração à comunidade acadêmica e na constituição interdisciplinar da equipe desenvolvedora. Esta metodologia parte de um pressuposto interdisciplinar que articula quatro princípios avaliativos: o da interface gráfica, o educacional, o da programação e o administrativo. Com isto, buscou-se uma forma de catalogar as questões levantadas por projetistas e usuários sobre o ambiente.

\section{ROODA: o processo de institucionalização}

O processo de institucionalização do ROODA na UFRGS iniciou em 2003, quando a Secretaria de Educação à Distância (SEAD) convidou-o oficialmente para fazer parte do projeto de Educação a Distância desta universidade. Este convite teve como base as discussões do Fórum EAD/ UFRGS sobre as vantagens e as desvantagens de se desenvolver um AVA pela própria universidade. Concomitantemente, se fez um levantamento dos grupos de pesquisa da instituição que trabalham com a construção de ferramentas para EAD, a fim de averiguar as condições materiais e humanas disponíveis. Concluiu-se que o ROODA ${ }^{\text {ii }}$ estava dentro dos padrões almejados, mas era necessária sua reconstrução, o que teve como pressupostos o Plano de Desenvolvimento Institucional (PDI) e o Projeto Político-Pedagógico (PPP) debatidos nos Fóruns EAD.

Este ambiente foi desenvolvido por uma equipe interdisciplinar do NUTED, que está dividida nas sub-equipes da educação, da programação e do design. Seus integrantes eram vinculados à UFRGS, sendo: professores e graduandos dos cursos de Comunicação Social e Pegadogia, graduandos em Informática, pós-graduandos em Educação (PPGEDU) e em Informática na Educação (PPGIE) e bolsistas DTI/CNPq. Isto possibilitou o confronto de idéias, colaborando para a construção de um AVA mais consistente epistemológica e tecnologicamente (Leite e Behar, 2005).

Com o intuito de dar suporte a diferentes práticas pedagógicas, foram projetadas vinte funcionalidades para a nova versão do ROODA, sendo que o professor pode habilitá-las ou desabilitá-las para suas disciplinas. A distribuição dos recursos visa possibilitar associações entre a simbologia apresentada e os possíveis caminhos, contribuindo para uma lógica de organização que facilite a navegação. Também são disponibilizados três temas para a interface gráfica que podem ser selecionados pelo usuário, são eles: Fotográfica (Figuras 1 e 2), Aqua e Grafite. Assim, os usuários podem explorar o ambiente a partir de seus interesses acadêmicos, constituindo-o enquanto um espaço propício às redes de interações. 


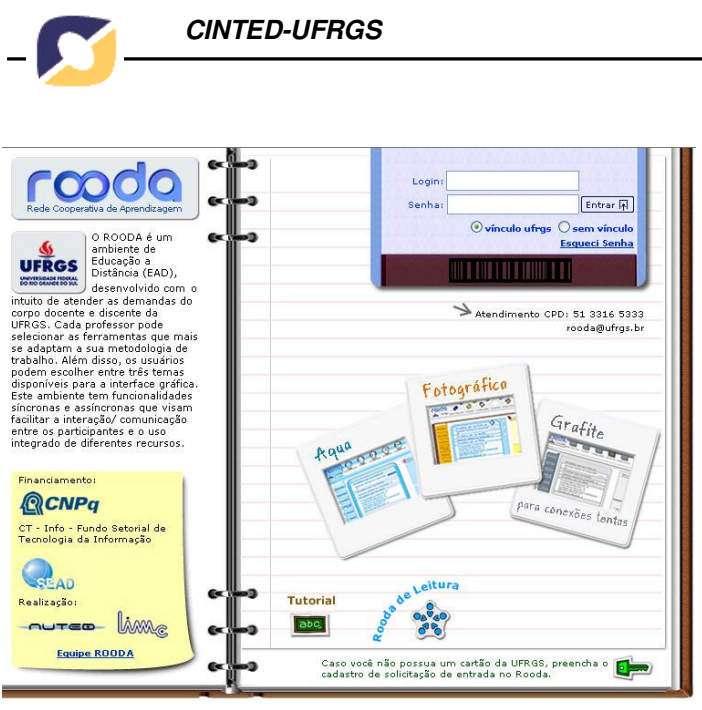

Figura 1- Tela de acesso ao ROODA, usada para login.

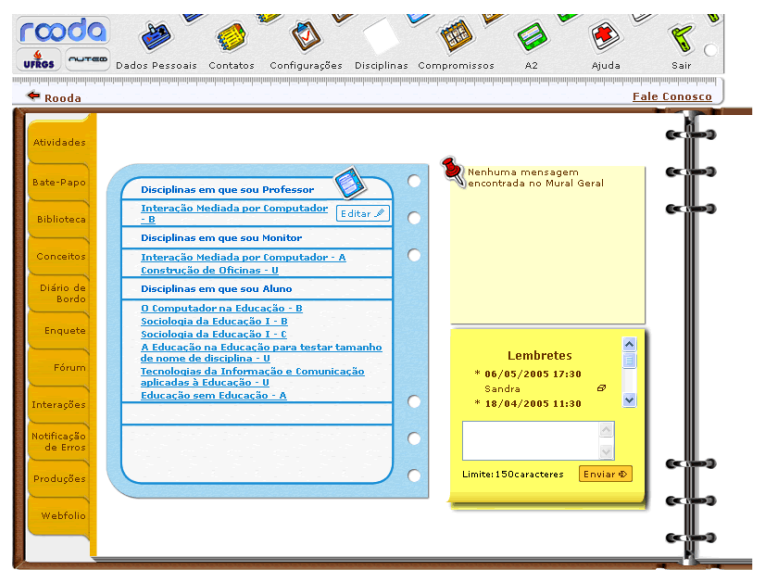

Figura 2- Tela Inicial, acessada após o login, com tema Fotográfico.

Em vista da quantidade de funcionalidades, buscaram-se meios de orientar o usuário na localização dos elementos dentro do ROODA. Principalmente os usuários sem afinidade com as tecnologias digitais. Para tanto, existe a hierarquia de navegação que indica o caminho do usuário dentro do sistema. Também é oferecido o recurso Ajuda, que divide-se em: Tutorial (através de animações, mostra como navegar no ambiente); Glossário (apresenta expressões usadas no ROODA e na Internet) e ajuda por Funcionalidades (descrições detalhadas sobre as funções e recursos das funcionalidades).

Em 2005, esta versão do ROODA começou a ser usada em nível de Graduação, PósGraduação e Extensão. Também começou a se fazer cursos de capacitação destinados a professores, monitores e técnico-administrativos. Este processo foi acompanhado pela SEAD, tendo em vista seu interesse em verificar o engajamento docente a este AVA na comunidade universitária, bem como divulgar a EAD na UFRGS. No primeiro semestre de 2005, o ROODA foi utilizado por 15 turmas de disciplinas das áreas de ciências exatas e humanas, engenharias e artes. Os usuários deste período inicial foram informados sobre o caráter experimental do ambiente e sobre a importância de suas contribuições no processo de aperfeiçoamento do mesmo.

No segundo semestre de 2005, o ROODA migrou para um servidor do CPD e foi integrado com o sistema da UFRGS. Neste semestre foram oferecidas 55 turmas de diversos cursos da UFRGS, ampliando o número de acessos e as experiências em diferentes navegadores. Além disso, foi automatizada a importação de informações referentes a atividades de ensino e corpo docente e discente. No primeiro semestre de 2006, o ambiente está sendo usado por cerca de 9000 usuários, que estão distribuídos em 350 cursos/disciplinas.

Juntamente ao processo de institucionalização, foi realizada a avaliação formativa do sistema, o que possibilitou rever seus recursos e implementar melhorias. Entende-se que este trabalho avaliativo pode influenciar na aprendizagem organizacional da UFRGS, elucidando suas potencialidades e carências da instituição. Além disso, pode subsidiar o planejamento de futuros investimentos materiais e humanos e contribuir para o autoconhecimento da comunidade envolvida (Leite, 2005). 


\section{O Processo Avaliativo do ROODA: uma proposta interdisciplinar}

A avaliação de AVA's é um processo contínuo e recursivo, que se constitui em um determinado contexto e atende a aspectos técnicos e epistemológicos. Para realizá-la, é necessário ter claro o que se pretende com o sistema, a que público se destina e quais os recursos humanos e materiais são essenciais para sua manutenção. Tal processo remete ao estudo das interações do usuário com o ambiente e com outros usuários através do ambiente. No caso do ROODA, isto envolveu uma equipe interdisciplinar e sua articulação com os outros setores implicados no processo de institucionalização.

O processo avaliativo de softwares destinados à educação, em especial AVA's, abarca uma coleta de dados sistematizada sobre maneira como os usuários utilizam o sistema. Estudos sobre este tema (Preece, Rogers e Sharp, 2005; Primo, 2003; Schlemmer e Fagundes, 2001) ressaltam que a avaliação pode ocorrer em diversos momentos do ciclo de vida do sistema, reorientando o processo e ampliando as possibilidades de fazer ajustes pertinentes. É importante investir no caráter qualitativo deste processo, destacando problematizações pertinentes à aprendizagem e enfocando aspectos como: ferramentas destinadas à interação e ao trabalho coletivo, características da interface gráfica, portabilidade do sistema, possibilidade de incorporação de novos recursos e onde o ambiente foi produzido.

Assim, o processo avaliativo realizado com o ROODA buscou considerar tanto a avaliação enquanto um processo institucional, quanto a avaliação do sistema computacional. Este processo avaliativo teve como ênfase sua proposta interdisciplinar, sendo orientado por quatro princípios interdependentes: da interface gráfica, o educacional, da programação e o administrativo. Nesta perspectiva, pode-se refletir sobre as questões levantadas, tratando ao mesmo tempo das especificidades e da abrangência pertinentes à utilização de um AVA em uma instituição como a UFRGS.

\subsection{Princípio da Interface Gráfica}

Este princípio diz respeito ao processo de elaboração e avaliação da interface gráfica de AVA's, mais especificamente do ROODA. Isto envolve: pesquisa com os usuários; reconhecimento de necessidades; planejamento da navegação e desenho do layout. Para Lévy (1993), o termo interface no campo da informática refere-se a um dispositivo que possibilita a comunicação entre sistemas informáticos distintos ou com sistemas de outra natureza. A partir disto, entende-se que a interface gráfica promove a tradução da linguagem binária utilizada na computação para uma linguagem visual interpretável, buscando que o usuário possa realizar suas tarefas com mais eficiência.

Para tanto, é importante considerar a usabilidade e o design como dois aspectos interdependentes, sendo que ambos são fundamentais na criação da interface. $O$ primeiro é entendido como a capacidade de tornar a experiência do usuário em um ambiente virtual mais eficaz, estando relacionado com a maneira que ele se orienta neste espaço. Já o segundo, diz respeito à disponibilização e à aparência dos elementos da tela, influenciando na escolha dos recursos como ícones, cores, formatação e animações. De acordo com Primo (2003), a interface de um AVA vai além de ícones e menus, atentando para aspectos técnicos, educacionais, artísticos e pessoais. Nisto, enfoca-se a busca por harmonia e coerência nos elementos usados e na lógica de organização, primando por uma padronização dos mesmos.

\subsection{Princípio Educacional}

O Princípio Educacional contempla a relação entre a concepção epistemológica que norteou o desenvolvimento do ROODA e as diferentes formas de uso do ambiente, buscando atender as necessidades do corpo docente e discente e dos técnico- 
administrativos da UFRGS. A concepção epistemológica deste ambiente embasa-se na teoria piagetiana (Piaget, 1973), segundo a qual, a construção do conhecimento se dá através da interação do sujeito com o objeto. É através deste processo que o sujeito se coloca no mundo e, com ele, estabelece uma ligação.

A fim de compreender as formas de uso do ROODA, são estudas as lógicas empregadas pelos usuários no ambiente. Com isto, pretende-se entender como eles organizam suas ações na esfera virtual em relação aos objetos de estudo. Também se enfoca as práticas pedagógicas dos professores, ou seja, a metodologia e a concepção epistemológica utilizada pelo docente. Nisto, propõe-se a investigação da interação do usuário com os diferentes objetos do ambiente, tais como: outros usuários (professores, monitores e alunos), funcionalidades, materiais publicados, produções dos demais usuários e seus próprios registros. Através dessas interações o usuário está experienciando dois aspectos interdependentes: o conteúdo da disciplina e a estrutura do AVA.

\subsection{Princípio da Programação}

O Princípio da Programação trata do desempenho do ROODA, mais especificamente das questões ligadas à programação e ao banco de dados. Com base em Deitel, Deitel e Nieto (2003), reflete sobre o conjunto ordenado de ações que caracterizam este sistema, a fim de que execute as operações de forma rápida e correta. Também aborda o armazenamento e a integração dos dados, bem como seu acesso e manipulação. A partir disto, discute-se sobre a estrutura e a lógica de funcionamento do ambiente, visando seu aperfeiçoamento constante e a sua utilização em diferentes browsers.

Com o processo avaliativo, investiu-se no desenvolvimento de técnicas de programação que melhorem o desempenho de aplicativos Web. Desta forma, buscaram-se novos recursos e tecnologias que pudessem reduzir o tempo de resposta às solicitações dos usuários. Os recursos encontrados foram avaliados em relação ao seu desempenho, o que inclui às necessidades tecnológicas do lado do cliente e o suporte a uma programação cross-browser (estilo de programação em que o código deve funcionar no maior número de browsers e em diferentes plataformas). Dentre as soluções adotadas pode-se citar a integração de: javaScript, XML, recursos do DOM (modelo de objetos do documento) e recursos de orientação ao objeto da linguagem PHP.

\subsection{Princípio Administrativo}

O princípio administrativo enfoca o gerenciamento do ROODA como um todo e das suas turmas isoladamente, bem como a relação destas duas instâncias com o processo de institucionalização do ambiente. Para atender os diferentes privilégios dos usuários nas diferentes situações, estabeleceu-se uma divisão para as atividades de gerenciamento: vínculo com o sistema (os administradores são classificados em grupos com permissões distintas) e vínculo com a turma (subdividido em professor, monitor e aluno).

Entende-se que a estrutura administrativa de um AVA deve atentar para a organização da instituição à qual ele se destina, a fim de atender as peculiaridades e nomenclaturas empregadas. Além disso, de acordo com Schlemmer e Fagundes (2001), deve permitir que o professor estabeleça relações entre suas concepções e a dos estudantes, possibilitando a adaptação às necessidades encontradas e desburocratizando o trabalho docente. Assim, além de vincular o acesso do ROODA ao acesso do portal de servidor/aluno da UFRGS e possibilitar a importação de dados do CPD, buscou-se formas de flexibilizar o trabalho docente. A partir disto, são oferecidos recursos que permitem ao professor: alterar as informações da turma, gerenciar e monitorar tarefas, criar espaços de combinações e levantamento de informações, exportar materiais e atividades de uma turma para outra, realizar atividades vinculadas às disciplinas ou fora de sua estrutura, fazer uma avaliação processual e/ou através de provas e sistematizar o 
registro de notas e/ou conceitos. Entende-se que a disponibilização destes recursos, bem como o estudo das formas que os usuários exploram-nos, contribui para que se crie uma estrutura administrativa consistente e condizente com as necessidades da instituição, a fim de se possibilitar o desenvolvimento de estratégias de gestão neste AVA.

\subsection{Proposta Interdisciplinar}

A proposta interdisciplinar que norteou a avaliação do ROODA se configura pela articulação entre os quatro princípios apresentados (da interface gráfica, educacional, da programação e administrativo). Ressalta-se que estes princípios apresentam especificidades oriundas das áreas que os originaram, mas na interação entre eles constitui-se uma realidade comum, que é o desenvolvimento e o aperfeiçoamento do ROODA. Para Piaget (1976) uma investigação interdisciplinar precisa definir os diferentes aportes teóricos e as fronteiras entre as disciplinas, a fim de delimitar melhor os mecanismos comuns e os espaços de intersecção. Através das coordenações entre as disciplinas, passa-se a trabalhar com dúvidas, incertezas e impasses, o que exige mobilizações de esforços e contribui para os avanços na construção de conhecimento.

Nesta perspectiva, as referências e concepções afetam umas às outras e possibilitam novas construções, gerando interconexões entre as disciplinas e a revisão de suas fronteiras. Como argumenta Axt (2000), isso contribui para o não-engessamento das delimitações de cada área, bem como para o questionamento de seus padrões, configurando-se um espaço de ação empírica, reflexiva e teórica. Assim, a proposta interdisciplinar se caracteriza pela interação entre os diferentes pressupostos presentes neste processo avaliativo. Ou seja, contempla um "lugar" de encontro entre as subequipes que trabalham no aperfeiçoamento do ROODA, o que ganha visibilidade com o objetivo comum dos projetistas. Para tanto, foram definidas estratégias investigativas que atendessem as peculiaridades dos outros quatro princípios e enfocassem as questões que estavam sendo abordadas durante a avaliação. Tanto os procedimentos avaliativos adotados quanto os resultados alcançados, refletem esta proposta.

\section{Procedimentos Avaliativos: Coleta de Dados}

Tendo em vista a importância da avaliação na construção de um sistema computacional como o ROODA, esta prática esteve presente em várias fases do seu ciclo de desenvolvimento. Para esclarecer melhor como foram coletados os dados nos decorrer do processo avaliativo, dentro de uma proposta formativa, este foi dividido em três etapas: 1) planejamento e implementação, 2) testes feitos pela equipe projetista e 3) experiências realizadas com usuários da comunidade da UFRGS. Com isto, pode-se avaliar sua performance diante de situações hipotéticas e situações reais, com diferentes sistemas operacionais e navegadores.

A primeira etapa avaliativa foi realizada pela equipe de projetistas e contempla o planejamento e a implementação do ROODA, que iniciou em julho de 2003 e se estendeu até novembro de 2004. Neste período foram feitas reuniões com a equipe, a fim de projetar os recursos que seriam oferecidos no ambiente. Nestas, eram trazidos exemplos de pesquisas realizadas com AVA's e de experiências pessoais dos projetistas. Conforme cada funcionalidade era definida, a sub-equipe do design construía uma primeira versão das telas, que eram analisadas pela sub-equipe da educação. Quando o layout de todas as funcionalidades ficou pronto, a equipe interdisciplinar reuniu-se para fazer uma avaliação do projeto gráfico e da navegação no ROODA, a fim de encontrar inconsistências e apontar alternativas para melhorá-lo. As telas corrigidas guiaram a modelagem e a programação das funcionalidades (Leite e Behar, 2005). 
A segunda etapa avaliativa, que contempla o período de testes feitos pelos projetistas, aconteceu entre outubro de 2004 e março de 2005. Os testes foram realizados pelas subequipes do design e da educação, que discutiam sobre as inconsistências e erros encontrados e repassavam-nos aos integrantes da sub-equipe da programação. Nesta etapa, teve-se a preocupação de fazer testagens em navegadores diferentes, também se buscou criar situações hipotéticas de professor, monitor e aluno. Assim, muitos problemas foram detectados e corrigidos, minimizando as possibilidades de falhas no ambiente. É necessário ressaltar que a grande maioria dos usuários do ROODA não está habituada com este tipo de recurso e que os erros no sistema podem contribuir para um distanciamento entre estes usuários e as práticas pedagógicas em AVA's.

A terceira etapa avaliativa foi realizada pelos projetistas juntamente com servidores e alunos da UFRGS, durante o primeiro e o segundo semestre letivo de 2005. Através dela, pode-se acompanhar o ROODA em situações reais de uso e levantar dados a partir das questões trazidas pelos usuários. Junto a isto, fizeram-se reuniões com integrantes da SEAD e do CPD, o que possibilitou a troca de idéias entre os setores e a busca de soluções viáveis para os problemas encontrados, principalmente no que tange a integração do ROODA com o sistema do CPD. Tendo em vista a quantidade de questões trazidas pelos usuários, foi necessário sistematizar a coleta e organização dos dados, conforme é apresentado a seguir.

\subsection{Coleta de dados na comunidade da UFRGS}

O início das atividades letivas no ROODA foi pontuado por uma preocupação dos projetistas em atentar para as questões trazidas pelos usuários, a fim de propor melhorias e adequá-lo às demandas detectadas. Para tanto, estabeleceram-se canais de comunicação com os usuários, possibilitando a manifestação de dúvidas, críticas, sugestões e elogios. Destes canais, destacam-se:

a) Notificação de Erros - recurso disponibilizado no ROODA a todos os usuários apenas no primeiro semestre de 2005. Através de seus registros buscou-se agilizar e otimizar o processo de aperfeiçoamento do ambiente, como pode ser observado no exemplo abaixo (Figura 3).

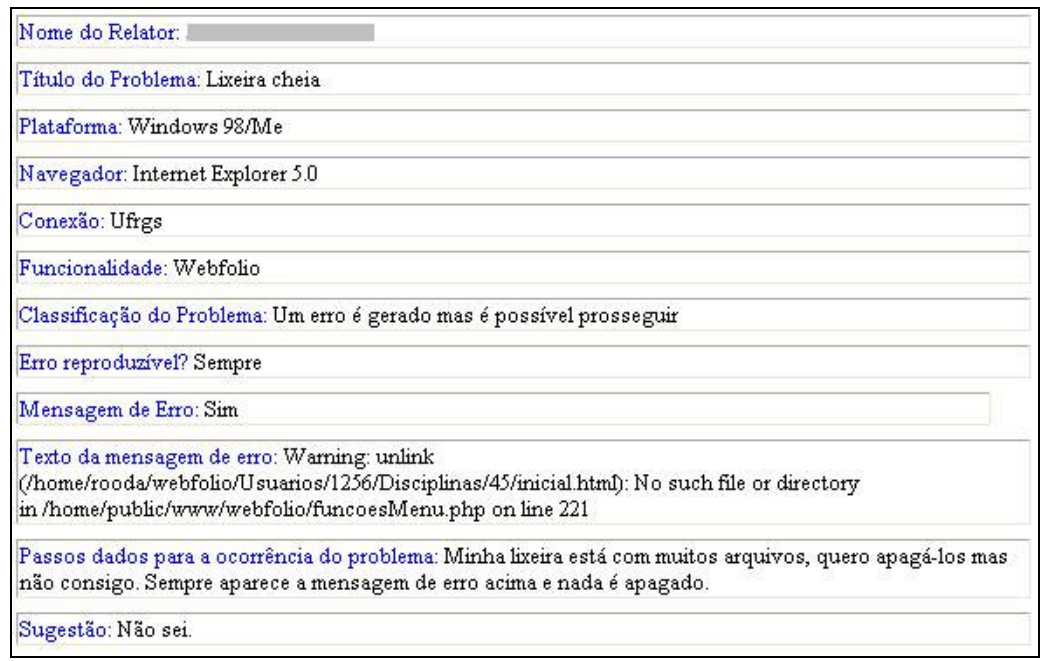

Figura 3 - Registro feito no recurso Notificação de Erros

b) Fórum - funcionalidade destinada à comunicação assíncrona. Muitas vezes os usuários usavam-na para narrar erros no sistema e problemas que encontravam no 
manuseio do AVA, pedindo auxílio e dando sugestões, o que pode ser observado no registro abaixo.

FÓRUM - (25/04/2005 16:51) - USUÁRIA ( ALUNO)

Que ódio!!

Fiquei duas horas escrevendo uma mensagem e quando fui enviar ela sumiu!!!

Bom... vou começar de novo... Estava dizendo que os meus entrevistados preferem um professor humano (simpático, acessível) a um figurão (super da área). O que acham??

Pendurei meu texto no webfólio há tempo, mas parece que ninguém estava visualizando. E agora, estão??

Respondi uma mensagem de uma colocação de uma colega, mas não gostei desse formato. Se quisermos comentar mais de um tópico, fica difícil de manter um diálogo!!

Que tal se sempre criarmos um novo tópico, mesmo para responder?? Não sei... espero resposta, se conseguir enviar esse texto...

Há, será que alguém poderia responder o Diário de Bordo?? Deixei uma perguntinha lá: HELP!!

c) Diários de Bordo - funcionalidade destinada aos registros pessoais. Muitas vezes, os alunos usavam-na para narrar situações de conflitos em relação ao ROODA e às práticas pedagógicas no ambiente, também foram encontrados depoimentos sobre a aprendizagem e o trabalho em AVA's. Conforme o relato abaixo.

\section{DIÁRIO DE BORDO - (01/07/2005 20:21) - USUÁRIA ( ALUNO)}

É muito positivo o fato de o aluno poder realizar uma atividade ocupando seus horários livres; bem mais proveitoso do que realizar uma atividade em uma semana cheia de outras provas e trabalhos, o que acaba acontecendo em disciplinas presenciais. Particularmente, achei muito legal a disciplina, tanto a metodologia de ensino quanto os assuntos que foram abordados. Espero que mais professores do ICTA se "modernizem" e utilizem dessa ferramenta, pois é uma forma de aprendizado muito válida.

Quanto a plataforma Rooda, só tive problemas com vídeos, não consegui assisti-los. No mais, foi tranqüilo.

d) A2 - funcionalidade que possibilita a comunicação síncrona entre os usuários que estão conectados no ROODA. Em alguns casos, os usuários encontravam no A2 integrantes da equipe de projetistas e tiravam suas dúvidas ou apontavam erros que impediam a realização de alguma tarefa, como pode ser acompanhado no trecho abaixo.

A2 - (25/08/2005)

USUÁRIO (25/8/2005 17:41)

hehehe, tô por aqui também... :cp tô vendo quem eu acho pelo msn, pra perguntar se conseguiu ou não acessar o rooda, e se não, porquê.

PROJETISTA (25/8/2005 17:42)

que legal... essa informação é pertinente

USUÁRIO (25/8/2005 17:51)

tô fazendo o teste com a (outra usuária) agora... cuida se ela aparece aí, não me lembro se ela é da comunicação visual A ou B...

PROJETISTA (25/8/2005 17:51)

ok

PROJETISTA (25/8/2005 17:53)

O NOME DELA não apareceu...

PROJETISTA (25/8/2005 17:53)

ela é dessas disciplinas mesmo?

USUÁRIO (25/8/2005 17:54)

sim, comunicação visual, turma A. 
e) E-mails enviados e ligações telefônicas feitas para o NUTED - foi criado um endereço eletrônico oficial (rooda@ufrgs.br) que centralizou as mensagens enviadas para a equipe. Também eram feitas ligações para o núcleo, principalmente por docentes, com questões mais urgentes e que precisavam ser resolvidas o quanto antes. É apresentado abaixo o trecho de uma mensagem enviada por um docente da UFRGS aos projetistas do ROODA.

\section{E-MAIL - (06/05/2005 13:24) - USUÁRIA ( DOCENTE)}

Quanto a solicitaçao de receber mensagens quando alunos postassem no webfolio, diario de bordo e forum, considero que isso agilizaria minha atividade, pois atualmente preciso ficar clicando nome por nome na lista de alunos, ora no webfolio, ora no diario de bordo, para verificar se postaram algo. Conforme e-mail que (usuário - monitor) enviou quarta-feira, isso poderia ser uma funcionalidade a ser ativada ou não por cada docente.

f) Monitorias à distância em disciplinas oferecidas no ROODA - alguns integrantes da sub-equipe da educação estavam cadastrados como monitores das disciplinas, a fim de acompanhar as atividades letivas e dar suporte técnico à distância aos docentes. Com isto, pode-se observar o funcionamento das disciplinas e o uso das funcionalidades.

g) Conversas Informais - existiam usuários do ROODA que conviviam com projetistas da equipe em outras esferas da UFRGS, o que possibilitava relatos de experiências e sugestões de melhorias em situações mais informais.

A partir dos dados coletados e dos princípios apresentados, vislumbraram-se: erros e inconsistências no sistema, diferentes formas de usar os recursos, comandos confusos e falta de clareza em expressões e cores usadas na interface gráfica. Também se observou a necessidade de novas adequações do ROODA à estrutura da instituição, à terminologia acadêmica e aos padrões do CDP. Assim, foi essencial pensar um modo de catalogar os dados coletados, a fim de orientar o trabalho da equipe projetista.

\subsection{Catalogação e Classificação dos Dados Coletados}

A fim de definir como seria feita a organização dos dados coletados durante a terceira etapa do processo avaliativo, foram consultadas algumas formas de sistematizar o acompanhamento aos problemas detectados. Dentre estas, destaca-se a apresentada por Preece, Rogers e Sharp (2005, p. 353), que montou um ranking de problemas organizados nas colunas: questão \# (com o número referente), prioridade (alta, média ou baixa), questão (com a descrição do problema) e recomendação (sugestão de como corrigir o problema).

A partir deste levantamento e da proposta avaliativa da equipe, montou-se uma tabela para cada funcionalidade (Tabela 1), a fim de catalogar e classificar os dados coletados. Esta tabela foi dividida em: Data-Problema/Sugestão, Prioridade e Dificuldade/Tempo. No item Data-Problema/Sugestão a sub-equipe da educação registrava as modificações propostas para as funcionalidades e sua data. O item Prioridade foi classificado em 1urgente, 2-importante e 3-interessante, ficando a critério da sub-equipe da educação, que estava responsável pelo atendimento aos usuários. Por fim, o item Dificuldade/Tempo foi classificado em Difícil, Médio e Fácil. Este último item ficava a critério das subequipes da programação e do design, que eram responsáveis pela implementação das modificações. 
Tabela 1 - Catalogação e classificação dos dados

\begin{tabular}{|c|c|c|c|}
\hline \multicolumn{4}{|l|}{ FUNCIONALIDADE: Atividades } \\
\hline $\begin{array}{c}\text { Data } \\
\text { Problema/ Sugestão }\end{array}$ & $\begin{array}{c}\text { Prioridade } \\
\mathbf{1}-\text { Urgente } \mathbf{2}-\text { Importante } \\
\mathbf{3} \text {-Interessante }\end{array}$ & $\begin{array}{c}\text { Dificuldade/tempo } \\
\text { Difícil Médio } \\
\text { Fácil }\end{array}$ & Ok \\
\hline $\begin{array}{l}\text { 14/04/05 } \\
\text { SUGESTÃO: Quarta opção de } \\
\text { atividade: Página WEB. }\end{array}$ & 1 - urgente & Fácil & $\mathrm{X}$ \\
\hline $\begin{array}{l}\text { 14/04/05 } \\
\text { PROBLEMA: Visualização de arquivo } \\
\text {.pdf - o sistema avisa que o arquivo não } \\
\text { foi encontrado. }\end{array}$ & 1 - urgente & Médio & $\mathrm{X}$ \\
\hline $\begin{array}{l}\mathbf{2 5 / 0 5 / 0 5} \\
\text { SUGESTÃO: Possibilidade de mudar a } \\
\text { ordem das atividades, para que as } \\
\text { atividades mais recentes sejam as } \\
\text { primeiras, e por consequiência, as mais } \\
\text { antigas sejam as últimas. }\end{array}$ & 2 - Importante & Fácil & $\mathrm{X}$ \\
\hline
\end{tabular}

Esta forma de registro e organização dos dados coletados possibilitou que a equipe dimensionasse o que precisava ser feito, auxiliando na distribuição das tarefas e agilizando as trocas entre os projetistas. É preciso destacar que os registros nas tabelas, geralmente, eram acompanhadas de conversas entre os integrantes da equipe, que discutiam sobre a viabilidade das modificações propostas.

\section{Aperfeiçoando o ROODA: mudanças implementadas}

O processo avaliativo realizado com o ROODA foi marcado pela estrutura interdisciplinar da equipe de projetistas e pela sua institucionalização. Nisto, as melhorias implementadas no ambiente refletem a interdependência entre os princípios apresentados, de modo que as questões levantadas foram analisadas a partir dos diferentes enfoques. No decorrer das três etapas avaliativas, muitos detalhes foram sendo corrigidos e pormenores, que poderiam passar despercebidos, eram detectados e revistos. Entretanto, este processo não pode ser resumido à correção de bugs, pelo contrário, ele envolveu o entendimento do ROODA como um todo, visto que o sistema vai além da união de várias funcionalidades.

Dentre as mudanças implementadas, destaca-se a ampliação do módulo administrativo do sistema, que passou a permitir a configuração de grupos de usuários com diferentes permissões. Isto possibilita a adequação do gerenciamento do ambiente ao gerenciamento da UFRGS. Estes grupos poderão ser criados e editados pelo administrador nível um, que tem plenos poderes, o que será feito a partir de contatos com o CPD e com as unidades da UFRGS. Além disso, também foram implementados os recursos Estatísticas do Ambiente (disponibiliza informações numéricas sobre acessos, disciplinas e turmas) e E-mail para os Usuários (possibilita o envio de mensagens eletrônicas para todos os usuários ou para casos específicos).

Das vinte funcionalidades disponíveis no ROODA, três sofreram alterações significativas em seus recursos. São estas:

Atividades - Implementou-se os recursos: Exportar, que permite ao professor utilizar a mesma atividade em outra disciplina do ROODA; a opção de atividade Página WEB, com campo para inserir um link da Internet; e a descompactação de arquivos, no caso de atividades criadas através de envio de arquivos. As atividades passaram a ser listadas em ordem decrescente de criação e esta funcionalidade será desmembrada em duas abas - Aulas e Exercícios. 
Fórum (Figura 4 e 5) - Reorganizou-se a disponibilização de mensagens, possibilitando que o usuário escolha se deseja visualizá-las ordenadas por Árvore, Data ou Autores. Ao habilitar o Fórum para sua disciplina, o professor seleciona se a criação de tópicos poderá ser feita somente pelos formadores ou por todos. Quando o usuário posta uma mensagem, ele tem cinco minutos para editá-la ou apagá-la.

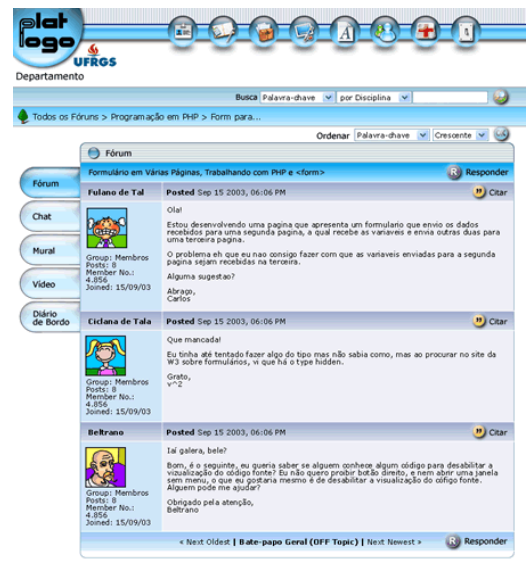

Figura 4 - Primeira versão da Tela do Fórum, antes do aperfeiçoamento (Tema Aqua)

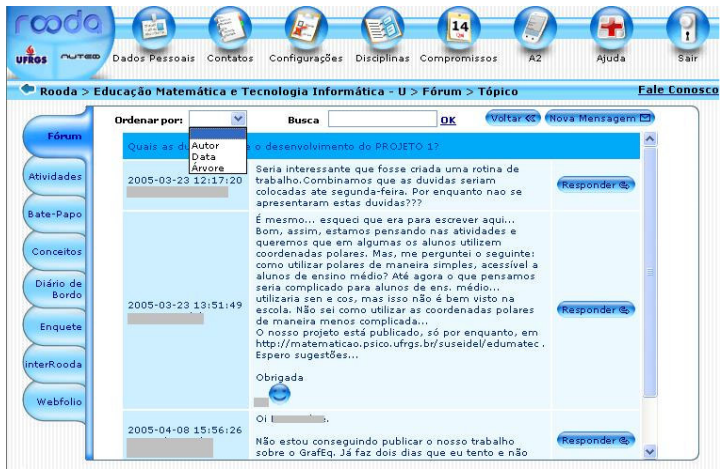

Figura 5 - Tela do Fórum após a implementação das melhorias (Tema Aqua)

Webfólio (Figura 6 e 7) - Acrescentaram-se abas que subdividem a funcionalidade em Geral, Disciplinas e Produções, separando as publicações. Além disso, o usuário configura se arquivos e pastas serão visíveis para Ninguém, Formadores ou Todos. Em Webfólio da Produção, somente o professor responsável e o administrador da produção podem apagar os arquivos da lixeira.

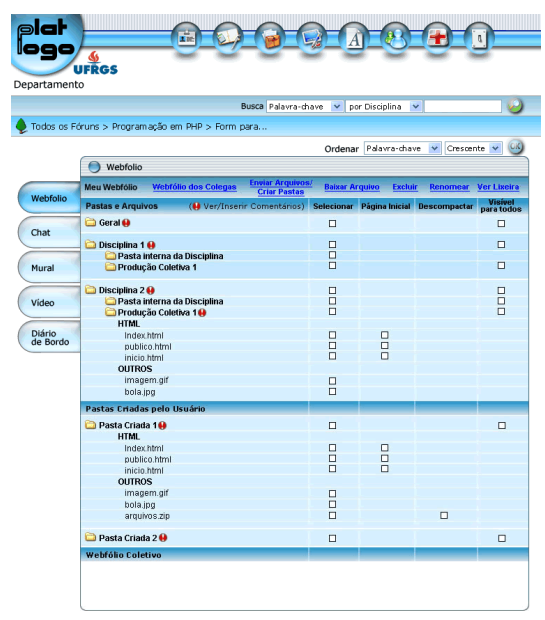

Figura 6 - Primeira versão da Tela do Webfólio, antes do aperfeiçoada (Tema Aqua)

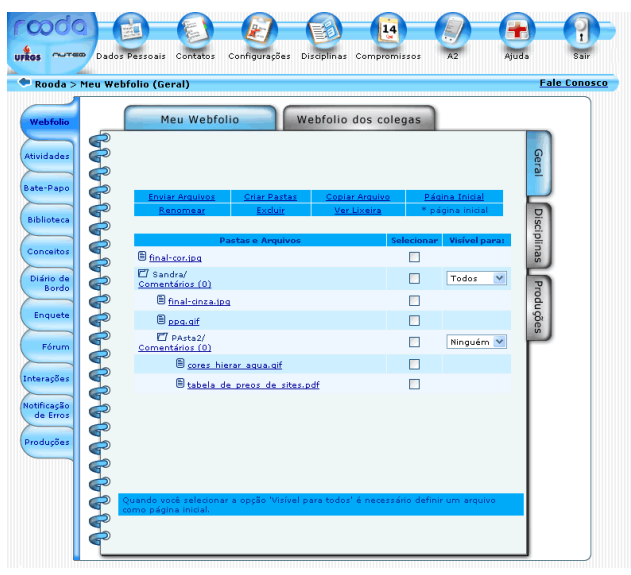

Figura 7 - Tela do Webfólio após a implementação das melhorias (Tema Aqua)

Nas funcionalidades que possibilitam a inserção de comentários, como Diário de Bordo e Webfólio, adotou-se uma sinalização que indica: 1) se existe comentário postado por formador; 2) se existe comentário postado por colega; e 3) ao formador que ele já postou comentário àquela mensagem. Além disto, e de outros pequenos ajustes que não foram citados neste artigo, também se alterou a Hierarquia de Navegação, que passou a 
ter o texto em negrito para ficar em destaque e auxiliar na localização do usuário dentro do ambiente. Ressalta-se que, com a divisão da funcionalidade Atividades em Aulas e Exercícios, o ROODA passa a ter 21 funcionalidades, destas, 9 são específicas.

\section{Considerações Não-Finais}

A partir das questões apresentadas neste estudo, entende-se que a avaliação de AVA's não se resume à correção de bugs e melhorias superficiais. Este processo envolve a articulação entre pressupostos educacionais, da programação e do design, a partir de uma perspectiva interdisciplinar. Também é preciso compreender o contexto no qual a avaliação está sendo feita, a fim de definir princípios e estipular critérios condizentes com as demandas encontradas e com a viabilidade das sugestões apresentadas. Destacase que o processo avaliativo contempla uma dimensão educativa, tendo em vista a sua responsabilidade social e a constante construção de conhecimento. Com isto, é preciso criar estratégias que sistematizem a coleta e a catalogação dos dados, o que permite acompanhar a evolução do software, estabelecer padrões e documentar problemas e decisões. Tais estratégias possibilitam que os erros não sejam repetidos, dinamizam as trocas entre os projetistas e subsidiam futuras deliberações.

Nesta perspectiva, a avaliação realizada com o ROODA se destaca pelo seu caráter educativo, abrangendo a aprendizagem dos seus desenvolvedores e da própria instituição, o que foi permeado pelo entendimento sobre a utilização de um AVA e como se configura o seu processo de institucionalização. Para tanto, foi imprescindível a participação da equipe de projetistas, de setores da UFRGS (como SEAD e CPD) e dos usuários (professores, monitores e alunos). Todos os envolvidos tanto na equipe quanto de fora, trouxeram problematizações, refletiram sobre as questões apresentadas e buscaram soluções para os impasses. Sem esta participação, muitos problemas não teriam sido detectados e resolvidos. Todavia, este processo nunca se esgota, pois sempre que um sistema computacional estiver sendo testado/validado ou sendo utilizado em larga escala, novas questões serão levantadas e novos recursos precisarão ser projetados/implementados.

Com as modificações executadas no ROODA, busca-se atender as demandas encontradas na UFRGS, a fim de ampliar suas possibilidades de uso e aumentar seu ciclo de vida na instituição. A partir disto, propõem-se investigar o impacto do processo de institucionalização de uma AVA na universidade, bem como a constituição de novos espaços pedagógicos do ROODA. Também, entende-se ser importante estudar como a utilização deste ambiente pode contribuir para a melhoria da qualidade de ensino e uma aprendizagem mais efetiva nos diferentes cursos.

Atualmente, novos recursos estão sendo desenvolvidos para o ROODA. Um deles é a funcionalidade ROODA EXATA, um editor de fórmula matemática que será disponibilizada nas funcionalidades destinadas à comunicação síncrona e assíncrona, possibilitando que se edite e compartilhe fórmulas com caracteres da matemática e da física. Também está em fase de planejamento uma funcionalidade disponibilizada somente para os professores, denominada Documentação Pedagógica, que visa oferecer um espaço para os registros referentes ao andamento das turmas. Além disso, será feita: a ampliação da funcionalidade inteROODA (com mais opções de recursos e suporte para pesquisa qualitativa), a incorporação do editor de texto coletivo ETC e implementação de recursos de acessibilidade.

Assim, pretende-se dar continuidade a este processo avaliativo, tendo como base a perspectiva interdisciplinar e os quatro princípios apresentados (da interface gráfica, o educacional, da programação e o administrativo), pois se entende que o aperfeiçoamento do ROODA depende deste caráter contínuo e abrangente. Novas 
etapas avaliativas serão propostas, articulando-as às novas etapas da institucionalização. Com isto, busca-se que este ambiente seja utilizado amplamente na UFRGS, atendendo as demandas docentes e discentes nos diferentes níveis de ensino.

\section{REFERÊNCIAS BIBLIOGRÁFICAS}

AXT, M. Tecnologias Cognição Conhecimento: Um debate em aberto e interdisciplinar. Revista Informática na Educação: Teoria \& Prática, Porto Alegre, v.3, n.1, p.7-9, 2000.

BEHAR, P.; PINHEIRO, A.; KIST, S.; BITTENCOURT, J.. A Study of Interface for ROODA environment In: Computers and Education - Towards a Lifelong Learning Society. Holanda: Kluwer Academic Publishers, v.1, 2003. p. 25-36.

BEHAR, P.; PRIMO, A.; LEITE, S.M. ROODA/UFRGS: uma articulação técnica, metodológica e epistemológica. In: BARBOSA, R. (Org.). Ambientes Virtuais de Aprendizagem. Porto Alegre: Artmed, 2005. p. 51-70.

DEITEL, H; DEITEL, P.; NIETO, J. Internet e World Wide Web: Como programar. 2ed. Porto Alegre: Bookman. 2003.

LEITE, D. Reformas Universitárias: Avaliação Institucional Participativa. Petrópolis: Vozes. 2005.

LEITE, S.M.; BEHAR, P. O desenvolvimento de ambientes virtuais de aprendizagem por grupos interdisciplinares: a experiência do Projeto ROODA. In: Congresso Internacional de Educação, IV, 2005, São Leopoldo. Anais... v. único. CD-ROM

LÉVY, P. As Tecnologias da Inteligência. São Paulo: Editora 34. 1993.

PIAGET, J. Estudos Sociológicos. Rio de Janeiro: Forense. 1973.

PIAGET, J. Problemas Gerais da Investigação Interdisciplinar e Mecanismos Comuns. 2ed. Lisboa: Livraria Bertrand. 1976.

PREECE, J.; ROGERS, Y.; SHARP, H. Design de Interação: além da interação homem-computador. Porto Alegre: Bookman. 2005.

PRIMO, A. Interação mediada por computador: a comunicação e a educação a distância segundo uma perspectiva sistêmico-relacional. Tese (Doutorado). PósGraduação em Informática na Educação, Universidade Federal do Rio Grande do Sul, Porto Alegre. 2003.

SCHLEMMER, E; FAGUNDES, L. Uma Proposta de Avaliação de Ambientes Virtuais de Aprendizagem na Sociedade em Rede. Revista Informática na Educação: Teoria e Prática, Porto Alegre. v.4, n.2. p.25-36. 2001.

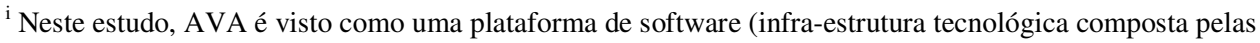
funcionalidades e interface gráfica), que dá suporte ao desenvolvimento de cursos via Web.

${ }^{\text {ii }}$ A versão anterior do ROODA, v. 0.7 beta, disponível em http://rooda.edu.ufrgs.br/, estava sendo usada por algumas turmas na UFRGS em caráter experimental. Esta versão também passou por um processo avaliativo, o que pode ser observado no trabalho publicado por Behar, Pinheiro, Kist e Bittencourt (2003).
} 